\title{
Serviço Social: Reflexões sobre as atuais tendências do mercado de trabalho do assistente social a partir de um estudo realizado com os alunos egressos do Curso de Serviço Social - UniFOA
}

\section{Social Service: reflections about nowadays social assistant job market tenden- cies taken from a study with Social Service Course-UniFOA egress students}

Artigo

Original

Original

Paper

Ursula Fraga Amorim ${ }^{1}$

Maria Augusta da Silva Tavares ${ }^{2}$

Palavras-chaves:

Serviço Social

Formação

Profissional

Mercado de

Trabalho

\section{Resumo}

O objetivo deste artigo é refletir sobre as atuais tendências do mercado de trabalho do assistente social tendo como base de reflexão, a pesquisa realizada com alunos egressos do curso de Serviço Social do Centro Universitário de Volta Redonda - UniFOA. O eixo metodológico de abordagem situa o atual quadro sócio-histórico em que as transformações em curso na realidade brasileira - repercutindo no "mundo do trabalho" apontam para um redimensionamento do Serviço Social e, em decorrência disso, na formação profissional e no mercado profissional de trabalho. Nesse sentido, a abordagem histórica sobre a formação profissional e o mercado profissional de trabalho tornou-se a tônica desse debate, uma vez que consideramos que os processos históricos são elementos chaves para a compreensão dos fenômenos sociais presentes na realidade atual. A pesquisa sobre uma realidade específica apresentou-se como condição essencial para uma complementaridade da abordagem teórica aqui destacada.

\begin{abstract}
The aim of this article is to reflect about nowadays social assistant job market tendencies having as a reflection basis the research done with egress students from the University Center of Volta Redonda Social Service Course. The methodological axis of approach presents the nowadays socialhistorical panorama in which the in course Brazilian reality changes which are reflected in job market - point to a Social Service re-dimensioning and, because of this, a re-dimensioning in the professional formation and in the professional job market. This way, the historical approach about professional formation and job market became the topic of this debate, once we consider that the historic processes are key elements for a comprehension of social phenomena present in nowadays reality. The research about an specific reality was presented as an essential condition to complement the theoretical approach highlighted here.
\end{abstract}

Key words:

Social Service

Professional

Formation

Job Market

\section{Introdução}

O mundo contemporâneo, especialmente nas últimas décadas, procedido por uma lógica societal que privilegia essencialmente a produção de mercadorias e a valorização do capital, é cenário de profundas transformações econômicas, sociais, políticas, culturais e ideológicas, estabelecendo grandes desafios às formas de sociabilidade humana. A crise vivenciada pelo capital, assim como suas argumentações, exteriorizada pela

\footnotetext{
${ }^{1}$ Mestre - Universidade Federal do Rio de Janeiro - CFCH/ESS Programa de Pós-Graduação - Mestrado em Serviço Social - Coordenadora Pedagógica -Programas de Especialização - UniFOA

${ }^{2}$ Mestranda - Programa de Pós-Graduação Em Serviço Social da Universidade Estadual do Rio de Janeiro - PPG-SS/UERJ
} 
reestruturação produtiva e o domínio neoliberal tem engendrado entre tantos embates, grandes alterações no "mundo do trabalho" e na esfera do Estado (ANTUNES, 1995).

De início, cabe destacar que o Serviço Social - "partícipe de processos de trabalho que se organizam conforme as exigências econômicas e sociopolíticas do processo de acumulação" (Iamamoto, 2001:95) - vivencia essas indicações e, requer uma apropriação dos processos macros da sociedade que circunscrevem qualquer tipo de trabalho, inclusive, o Serviço Social.

O cenário que vem alterando o mercado profissional de trabalho dos assistentes sociais tem suas origens na crise econômica mundial que data os anos 1970, quando Harvey identifica um conjunto de processos que solaparam o modo de produção fordista/keynesiano que, até então, regulava a economia internacional. Em decorrência disso, surgem, no cenário mundial, "novas experiências nos domínios da organização industrial e da vida social e política", bastante diferenciadas, denominadas pelo autor de "acumulação flexível", a qual apóia-se "na flexibilidade dos processos de trabalho, dos mercados de trabalho, dos produtos e padrões de consumo". (1989:140)

Como observa Iamamoto (2001), o processo de transformações que ocorre na esfera do trabalho implica alterações substanciais às demandas de qualificação de profissionais do Serviço Social, na medida em que requer uma formação profissional que possibilite aos assistentes sociais refletirem criticamente sobre as atuais tendências do processo de produção capitalista e seus reflexos nas funções tradicionalmente atribuídas à profissão e das novas formas de gestão da força de trabalho.

No que se refere às mudanças que vêm operando na esfera do Estado e das políticas sociais públicas, assistimos a um "ajuste" das diretrizes e ações governamentais através de uma ampla "Reforma do Estado", segundo diretrizes políticas de raiz neoliberal (IAMAMOTO, op.cit.).

Para o que nos interessa neste estudo, é preciso questionar os reflexos desse processo sobre o mercado de trabalho do assistente social. De acordo com Iamamoto, o processo em curso na realidade brasileira indica um redimensionamento no perfil do assistente social, isso porque a base material e organizacional do trabalho do assistente social depende das organizações públicas e privadas as quais atuam no campo das políticas sociais, e ao que tudo indica, essa base está "sofrendo uma mudança de forma" (op.cit.:183).

Tais mudanças decorrem das privatizações da esfera estatal, em acordo com as novas formas de gerenciamento e controle da força de trabalho no processo de produção. Neste quadro de mudanças, Iamamoto (op. cit.) indica uma diversidade de organizações não governamentais (ONGs) que demandam o trabalho do assistente social, as parcerias do Estado com as tradicionais organizações filantrópicas e com as empresas, a retração da prestação de serviços sociais realizadas diretamente pelas organizações do setor público estatal. A autora observa

uma transformação do tipo de atividades que foram tradicionalmente atribuídas ao assistente social, exigindo-lhe, por exemplo, cada vez mais sua inserção em equipes interdisciplinares, o seu desempenho no âmbito de formulação de políticas públicas, impulsionadas pelo seu processo de municipalização; o trato com o mundo da informática, a intimidade com as novas técnicas e discursos gerenciais, entre muitos outros aspectos, o que muitas vezes tem sido lido, enviesadamente como "desprofissionalização", "perdas de espaços", "restrição de suas possibilidades ocupacionais" (op.cit.:185).

$\mathrm{Na}$ perspectiva de Iamamoto (op. cit.), o que está por detrás desse discurso são as dificuldades de se apropriar das mudanças macrossociais que operam no campo profissional. Neste sentido, as agências de formação profissional devem assumir o compromisso de qualificar profissionais capazes de apreender criticamente o tempo presente, e, ao mesmo tempo, estimular sua capacidade de respostas às demandas que emergem do cotidiano profissional.

Compartilhamos da afirmação da autora quando diz que "a sintonia da formação profissional com o mercado de trabalho é condição para se preservar a própria sobrevivência do Serviço Social” (Iamamoto, op.cit.:172).

Afinado com esse debate, este artigo pretende produzir uma reflexão sobre o mercado de trabalho do Serviço Social a partir de uma pesquisa realizada com os alunos egressos do Centro Universitário de Volta Redonda UniFOA. 


\section{Uma revisão histórica do Serviço Social no Brasil}

Para situar o debate aqui proposto, trataremos de expor ainda que de forma concisa, uma revisão histórica do Serviço Social no Brasil, com vistas a apreender as particularidades da formação profissional e do mercado de trabalho e suas relações com os distintos processos sociais.

O Serviço Social, em sua trajetória histórica, passou por profundas transformações decorrentes das demandas sociais identificadas a cada conjuntura histórica. No Brasil, o Serviço Social surgiu como profissão, em meados da década de 1930. Procedida pela organização da classe trabalhadora que reivindica seus direitos, a "questão social" foi reconhecida pelo Estado e tratada através das políticas sociais, quando o assistente social passou a ser requisitado diretamente pelo bloco do poder para executar a função de mediador dos conflitos existentes entre capitalistas e classe trabalhadora.

A primeira Escola de Serviço Social foi criada em 1936, em São Paulo, pelo Centro de Estudos e Ação Social (CEAS), com forte influência da Doutrina Católica e européia. Para Iamamoto (2003), a origem da profissão no Brasil encontra-se intimamente vinculada a iniciativas da Igreja, que pretendeu estrategicamente qualificar o laicato, especificamente da parcela feminina, vinculada aos setores abastados da sociedade, com o objetivo de dinamizar sua missão política de apostolado social junto à classe trabalhadora.

Com base nos estudos de Faleiros, podemos destacar que, neste contexto histórico, o Serviço Social se alicerçou tanto no processo conservador de manutenção da ordem social como no processo de "renovação", uma vez que a "prática higienista" estabeleceu mudanças normativas (higiene social, controle biopsíquico, recuperação dos indivíduos) às famílias e indivíduos. O exercício profissional se pautou particularmente em ações educativas com vistas a alterar o comportamento das famílias e indivíduos em "situações-problemas" (1997:17).

Esse modelo de intervenção social se esgotou devido à dinâmica da sociedade capitalista, e, também, pela busca de novos referenciais críticos para o exercício profissional. Nos anos de 1940, as crescentes demandas por bens e serviços pressionaram o Estado a buscar uma ação assistencial para que ao mesmo tempo pudesse favorecer a acumulação capitalista e atender às necessidades dos trabalhadores. Assim, foram criadas e desenvolvidas as grandes instituições públicas e privadas, onde o quadro dominante da sociedade requisitou o Serviço Social para participar e implementar as políticas sociais (IAMAMOTO, 2003).

Neste quadro sócio-histórico, a profissão inscreveu-se na divisão social e técnica do trabalho e ampliou o mercado de trabalho, conferindo um caráter não liberal à profissão, emboratenhasidoregulamentado como profissão liberal no Brasil. Mas, as políticas sociais não foram eficientes, pois, o Estado brasileiro de caráter paternalista e repressor, fragmentou sua efetivação, e conseqüentemente, as ações sócio-educativas do assistente social também se fragmentou, impossibilitando ações coletivas. $\mathrm{O}$ Serviço Social sob a influência norte-americana de pensamento positivista, mais uma vez teve a função de ajustar os indivíduos à ordem social vigente.

A década de 1950 teve como preocupações a reconstrução do pós-guerra, a libertação do colonialismo, o combate ao comunismo e as tentativas de expansão do capitalismo internacional, exigindo um processo de modernização e ampliação das políticas sociais. As expectativas de desenvolvimento social e de efetivação do Estado de Bem-Estar Social absorveram, através das atividades de promoção social, a prática e a teoria da categoria profissional. "O cientificismo e a sofisticação técnica permeiam e desenham essa atividade" (SPOSATI, 1995:47).

Com a promessa de ascensão sócioeconômica, as atividades de desenvolvimento comunitário foram oferecidas às comunidades e regiões de carência sócio-econômica, na qual, pretendeu-se romper com o ciclo dependente e promover a integração de indivíduos no mercado de trabalho e na ordem social vigente. Importa frisar que essa ascensão atendia à economia capitalista e reiterava a submissão através do atendimento tutelado oferecido pelos programas assistenciais (SPOSATI, op.cit.).

No final da década de 1950, reconhecido no mercado de trabalho, o Serviço Social sofreu alterações em suas bases filosóficas do pensamento conservador e, propôs um trabalho direcionado às transformações e críticas ao sistema social. O "Movimento de Reconceituação" foi o marco para essa mudança, 
quando houve os primeiros contatos com o referencial marxista. Porém, essa aproximação com o pensamento marxista não enriqueceu o trabalho do assistente social, visto que a literatura utilizada para o debate teórico não sucedia dos estudos de Marx e sim, de autores que o traduziram.

Somente nos anos de 1980, Iamamoto enriqueceu o debate teórico utilizando estudos diretamente de Marx. Com ela, mais estudos e pesquisas de autores como José Paulo Netto, Vicente de Paula Faleiros, entre outros, fortaleceram o debate teórico da profissão fomentando o pensamento crítico-dialético. (MELO, 2001)

Importa salientar o processo de renovação que o Serviço Social sofreu no contexto da "autocracia burguesa". Os estudos de Netto indicam que até então, a categoria profissional manifestava "uma relativa homogeneidade nas suas projeções interventivas". Os eventuais confrontos tiveram um desfecho sem repercussões públicas e não provocaram fraturas no âmbito profissional. Esse quadro sofreu uma ruptura a partir do processo de laicização do Serviço Social frente às novas exigências postas pela "autocracia burguesa", no âmbito de formação e exercício profissionais. (2004:128)

O desenvolvimento econômico, no contexto da ditadura, produziu inúmeras expressões da "questão social", expressões essaS que eram "controladas" pelas políticas sociais centralizadas, em que os assistentes sociais foram requisitados a ocupar os espaços burocráticos e administrativos no âmbito do Estado e das empresas privadas. Esse Estado "racionalizado" para gerenciar o grande capital, alterou substancialmente as políticas sociais setorizadas e tornou-se o grande empregador dos assistentes sociais, condição que permanece até os dias atuais. (NETTO, op.cit.)

Mas, se o mercado de trabalho necessitava desse profissional nos moldes da "modernização", isso implicava numa reestruturação da formação profissional. Havia a necessidade de reformular as bases de formação e de expandir quantitativamente os setores educacionais do Serviço Social. Em pouco mais de uma década, expandiu-se consideravelmente o curso de Serviço Social nas universidades públicas e privadas. Netto (op.cit.) observa que esse processo de ensino merece algumas considerações porque demarcou a inserção do ensino de Serviço Social na universidade.

A título de informação, esta inscrição não é de cunho jurídico, uma vez que o reconhecimento do estatuto superior e acadêmico da profissão data do início da década de 1950; o que se apresenta como inovação é uma incorporação da formação profissional nas redes de relações próprias da universidade. Com a expansão do curso, foi necessário recrutar novos docentes, principalmente jovens recém-formados com disponibilidade de se envolverem e dedicarem intelectualmente, produzindo no bojo desse processo de formação profissional uma massa crítica que não existia anteriormente. Por isso mesmo, a relação do Serviço Social com a autocracia burguesa no Brasil, manifestou-se, na redefinição das bases de formação profissional com vistas à atender um mercado nacional de trabalho constituído no bojo da autocracia burguesa. (NETTO, op.cit.)

Segundo o autor, o processo de renovação do Serviço Social no Brasil assumiu três direções a partir da década de 1960. A primeira direção assumida é a perspectiva modernizadora que tem suas bases filosóficas advindas do pensamento positivista norteamericano. Essa perspectiva encontrava-se vinculada à ordem política e social procedente do golpe militar de 1964. Admitia-se, sem questionamentos, a ordem social estabelecida e buscava nesta teoria positivista aparatos instrumentais para intervenção profissional. Nota-se, portanto, que essa perspectiva assumiu um viés do pensamento conservador, uma vez que a proposta da profissão foi a de concentrar esforços na busca de manter a ordem burguesa ajustando os indivíduos dentro dessa ordem. $\mathrm{O}$ trabalho do assistente social fundamentou-se em valores e concepções "tradicionais" porque recaíam sobre os indivíduos as responsabilidades pelas demandas por eles apresentadas.

NoâmbitodoServiçoSocial, houveuma exigênciaquesetransformassesignificativamente o trabalho profissional para atender as demandas de um Estado "racionalizado" que passa a ser o grande empregador do assistente social e, com isso, reformulava-se e ampliava-se a formação profissional no espaço acadêmico, utilizando referenciais teóricos de base neopositivista norte-americana presentes na ditadura militar.

Ainda de acordo com Netto, em meados dos anos de 1970, propiciado pela crise da "autocracia burguesa", a hegemonia da perspectiva modernizadora é colocada 
em cheque, reduzindo "a sua expressão na (auto)representação dos assistentes sociais". Os segmentos diferenciados que resistiram às inovações dessa perspectiva, quer pela vinculação ao tradicionalismo, quer pela incompatibilidade ideopolítica face a ditadura militar, expressaram-se nas duas outras direções apontadas pelo autor. (op.cit.:156)

$\mathrm{O}$ segmento mais resistente às mudanças, assumiu, nos termos de Netto (op.cit.), a perspectiva de reatualização do conservadorismo. Tratava-se de uma vertente condicionada em restaurar os elementos das tradições históricas conservadoras da profissão, e integrá-los na prática e na própria imagem. Essa reposição se deu através de uma base teóricometodológica que se configurava como nova, repudiando as bases do pensamento positivista e do pensamento marxista. A proposta aqui era a de intervir através de uma visão microscópica do mundo, e deitava raízes no pensamento católico tradicional. Mas, o trabalho se realizou com um componente moderno inexistente no processo anterior que teve as suas bases expressas nos referenciais positivistas.

$\mathrm{O}$ que se reatualizou, segundo Netto (op.cit.), foi um esforço para fundá-la em matrizes intelectuais sofisticadas. Esse processo se favoreceu do descrédito do acervo positivista e da recusa às posições crítico-dialéticas advindas de uma leitura "mutilada" do marxismo no qual apropriou-se o Serviço Social. Aceitou-se naturalmente um "terceiro caminho" . É por isso, que a reatualização do conservadorismo se expressou inspirada na fenomenologia.

A terceira direção indicada por Netto (op.cit.) foi a perspectiva que propôs a intenção de ruptura com o Serviço Social "tradicional”. Ela trouxe em seu bojo o sentido de "romper" com o pensamento conservador porque encerrava uma crítica sistemática à formação profissional e aos suportes teórico-metodológicos e ideológicos. Essa vertente constituiu-se a partir do quadro de docentes que tiveram a sua formação no contexto da ditadura, nas vésperas do golpe militar de 1964

De início, a intenção de ruptura se expressou com a proposição do pensamento marxista, mas encontrou obstáculos de afirmação no contexto sociopolítico da ditadura. Sua representação foi o chamado "Método BH". Entretanto, quando a ditadura deu sinais de crise, o "marxismo acadêmico" se desenvolveu, e, passou a ser referência nas teses de mestrado em
Serviço Social. O acúmulo desse quadro tornouse possível a partir da abertura política que abriu espaço à transição democrática atraindo vanguardas profissionais.

A intenção de ruptura travou polêmica na profissão. Foi considerável a influência do pensamento latino-americano reconceptualizado no final da década de 1970. Para Netto (op.cit.), é fundamental assinalar que essa repercussão decorreu das condições de trabalho da categoria profissional com a aproximação geral da classe trabalhadora. Essa vertente é uma expressão que mantém os seus aspectos dominantes de oposição ao conservadorismo da profissão. No entanto, no perfil profissional há um hiato entre romper com a herança tradicional e os caminhos que possam viabilizar essa prática profissional, e, de fato, realizá-la.

De fato, o exercício profissional crítico e transformador numa sociedade onde o propósito de acumulação do capital com base na exploração da força de trabalho são escamoteados, torna-se uma tarefa complexa para os profissionais que atuam de modo limitado nas políticas sociais, se não houver um arcabouço teórico-metodológico, ético-político e técnico-operativo bem estruturado. (Pontes, 2000:37)

$\mathrm{O}$ autor argumenta, ainda, que a proposta do Serviço Social com base no pensamento crítico-dialético, é atuar como mediador entre os usuários das políticas sociais e o Estado. O Serviço Social não atua sobre uma única necessidade social, visto que a "questão social" se refrata e ganha múltiplas dimensões. Assim, uma das singularidades da profissão é atuar sobre várias necessidades na busca de viabilizar e garantir os serviços e direitos que os usuários demandam.

Esse novo perfil, fundamentado nos princípios de justiça, liberdade, eqüidade e democracia, assumido pela categoria profissional através do Código de Ética Profissional de 1993, tem procurado interferir no processo de reprodução da força de trabalho, tanto na dimensão objetiva, como também, na dimensão subjetiva, com a finalidade de reorganizar as relações sociais mediante o exercício profissional.

Acontece que, a partir dos anos de 1990, iniciam-se dois processos que se interrelacionam: a continuidade desse novo perfil assumido pela categoria profissional, e as ameaças que sofre diante das transformações 
sociais que definem uma nova etapa do sistema capitalista, representado pelas políticas neoliberais (NETTO, 1999).

Netto (op.cit.) diz ainda que, especificamente, na sociedade brasileira, o rebatimento dessa crise social é enunciado a partir de 1995, quando a elite brasileira ocupou os espaços políticos decisórios para difundir as idéias contidas na agenda neoliberal.

Observa-se de imediato, a contradição entre as propostas de trabalho do Serviço Social e as propostas em curso de uma política altamente racional e moderna que promove, em primeira instância, os desmantelamentos dos direitos sociais conquistados na "Constituição Federal de 1988", a "Reforma do Estado" e a implementação da macroeconomia em detrimento ao desenvolvimento social (NETTO, op.cit.).

Neste sentido, preservar esse novo perfil profissional é um grande desafio que deve ser enfrentado através de ações profissionais comprometidas com a qualidade dos serviços, juntamente com o apoio coletivo de diversos setores da sociedade que participam de propostas semelhantes e, do fortalecimento dos movimentos sociais que, atualmente, revelam-se recuados diante da "cultura do neoliberalismo". (NETTO, op.cit.)

\section{Reflexões sobre a formação profissional e o mercado de trabalho na contemporaneidade}

Vimos, a partir das reflexões até aqui apresentadas, que as condições e relações de trabalho do assistente social sofrem, diretamente, os impactos do conjunto de transformações que se opera nas esferas pública e privada. Mas, afinal, como intensificar e assegurar o projeto profissional no contexto atual? Quais perspectivas devem ser construídas pela categoria profissional? Há possibilidades de vislumbrar novos rumos para a profissão nos novos espaços de trabalho? Esses e outros tantos questionamentos merecem atenção e devem fomentar espaços de debates nos canais de interlocução da categoria profissional.

Compartilhamos da afirmação de Netto que, tratar de questões que envolvem o desenvolvimento do Serviço Social, no Brasil, na cena contemporânea é "um exercício intelectual e profissional legítimo e necessário". (1996:87) Por certo, essa afirmação sustenta nossas preocupações acadêmicas em discutir a formação profissional articulada com o mercado de trabalho dos alunos egressos da supracitada universidade, no sentido de assumir um compromisso que possa imprimir qualidade à formação profissional.

Para Netto (op.cit.), o atual quadro sócio-histórico é demarcado por "transformações societárias" que interferem diretamente na vida em sociedade e refletem intensamente sobre as profissões, seus campos de trabalho, suas bases teórico-metodológicas, suas funções sociais, etc. Em decorrência disso, o autor revela o quanto é necessário estabelecer estratégias de trabalho minimamente afinadas para responder às questões que emergem desse cenário.

A nosso ver, essas estratégias só podem ser construídas a partir do compromisso das unidades de ensino em Serviço Social em desvelar os dilemas que permeiam a formação profissional, sobretudo no atual quadro sóciohistórico. Neste sentido, a nossa proposta inicial de discussão gira em torno da formação profissional e dos dilemas nela contida, para, a seguir, discutir os novos espaços de trabalho do assistente social.

Refletindo sobre a formação profissional a partir dos anos 1980, Iamamoto questiona sobre as conquistas que devem ser preservadas e quais são os dilemas apontados neste debate. A autora reafirma a necessidade de direcionar o "processo formativo" para a construção de um perfil profissional dotado de competência teórico-crítica, com base nas principais referências do pensamento social na modernidade e suas repercussões no campo teórico-prático no Serviço Social. Diz, ainda, que o debate efetuado nos anos 1980, indicou um privilégio (ainda que não exclusivo) para uma teoria social crítica, capaz de revelar os fundamentos da produção e reprodução da "questão social". Este perfil deve ser dotado, também, de competência técnico-política, que avance no campo da pesquisa e da ação, para a construção de respostas profissionais que possam agregar forças sociais preocupadas com os valores democráticos. Ou seja, o que está em pauta é a defesa de um trabalho que envolve "a construção de uma nova cidadania coletiva, capaz de abranger as dimensões econômicas políticas e culturais da vida dos produtores de riqueza, do conjunto das classes subalternas" (2001:185).

Resumidamente, essas foram as 
perspectivas assumidas pelo novo Código de Ética Profissional em vigor que vem também fortalecendo o direcionamento do processo de formação profissional dos assistentes sociais.

De fato, Netto (1996) ressalta que na década de 1990, o Serviço Social se mostra no Brasil como uma profissão consolidada. No que se refere à formação profissional, poucos eram os estados da federação que não contavam com escolas de Serviço Social, formando um quadro de aproximadamente setenta unidades de ensino. Sobre a pós-graduação, o autor revela que sete universidades já registravam experiências importantes. A Associação Brasileira de Ensino em Serviço Social (ABESS) sofreu uma renovação e expressou-se como foro nos debates sobre a formação profissional. Procurava, também, desenvolver um órgão acadêmico de pesquisa (Centro de Documentação e Pesquisa em Serviço Social e Políticas Sociais - CEDEPSS).

Esse quadro de amadurecimento profissional teve seu ponto mais destacado na contribuição oferecida pelos assistentes sociais para a elaboração da Lei Orgânica de Assistência Social (LOAS). Nesse processo, os assistentes sociais ofereceram aportes à sociedade através de seus órgãos de representação. (NETTO, op.cit.)

Evidentemente, o cenário descrito pelo autor, parece revelador dos avanços obtidos pela categoria profissional. Todavia, é neste mesmo cenário que emergem questões e problemas herdados de um passado recente, ou mesmo aflorado pelo atual contexto; mas, sobretudo, “exprimindo a própria inserção do Serviço Social na malha das concretas relações da sociedade brasileira". (NETTO, op.cit.:108)

Parece-nos crucial, destacar algumas questões explicitadas por Iamamoto (2001) e, que são amplamente discutidas no universo tanto acadêmico quanto profissional do Serviço Social, a partir dos anos 1980. Tais questões giram em torno dos compromissos éticopolíticos e, também, dos paradigmas teóricometodológicos de análise sobre a realidade que norteia a ação profissional.

A primeira questão destacada pela autora diz respeito ao pluralismo e ecletismo. A discussão aqui, parece indicar a necessidade de uma "interlocução de paradigmas" no âmbito do Serviço Social, para que a profissão não se mostre alheia às múltiplas tendências teóricas que atravessam, hoje, a produção das ciências sociais.
Mas, o que emerge a partir dessas discussões é a de como sustentar "um debate teoricamente plural no Serviço Social, sem resvalar para os efeitos danosos derivados do ecletismo teórico". Para Iamamoto, a questão aqui é encaminhar esse debate de modo que possamos demonstrar o entendimento acerca da "perspectiva teóricometodológica marxiana, como baliza para elucidar o diálogo possível com as contribuições no campo do conhecimento, produzidas a partir de outras matrizes ou paradigmas analíticos, que enriquecem o acervo científico". (op.cit.:187)

De fato, o encaminhamento teóricometodológico nos centros acadêmicos deve ser cuidadosamente avaliado e amplamente discutido com os discentes para que os mesmos possam se apropriar das contribuições contidas neste debate e, assim, serem capazes de examinar, através de um diálogo crítico, os impasses teóricos por eles reconhecidos.

Outra questão, discutida neste contexto, diz respeito à história, teoria e metodologia no Serviço Social, que, para Iamamoto (op. cit.), constitui um dos eixos necessários da formação profissional. Essa questão referese à "explicação do Serviço Social no quadro de relações entre Estado e sociedade, em suas relações com o mundo do trabalho, com a trama do poder e com o universo da cultura". Em outras palavras, a proposta aqui, não é a de uma leitura histórica simplesmente como história do Serviço Social, mas sim a de construir um exame a partir da totalidade, com ênfase às determinações históricas na esfera da produção/ reprodução da vida social, e suas relações com as esferas políticas e com as representações culturais (científicas e ético-políticas) que, além de interferir, repercutiram nas sistematizações da prática e ações profissionais, na trajetória da profissão.

No âmbito acadêmico, esse enfoque tem produzido uma estruturação de disciplinas, que incorporam os fundamentos históricos, teóricos e metodológicos do Serviço Social. Em contrapartida, Iamamoto observa que isso requer um vasto investimento de pesquisa, por parte dos docentes, no sentido "de construir uma crítica teórica, historicamente balizada do processo de constituição e desenvolvimento teórico-prático da profissão" (op.cit.:191).

Uma questão não menos emblemática diz respeito a distância entre a teoria e a prática, ou, nas palavras da autora, "a distância constatada entre o tratamento teórico- 
sistemático das matrizes teórico-metodológicas e a quotidianidade da prática profissional". O destaque aqui, é a necessidade de trabalhar o "campo das mediações", que favoreça uma transposição no nível da abstração para as singularidades do exercício profissional, o que requer desenvolvimentos mais amplos.

Sem dúvida, essa questão é amplamente discutida no âmbito acadêmico e profissional, sobretudo quando o discente passa a ter contato com o campo de estágio. Compartilhamos da afirmação de que "o dilema metodológico é o de detectar as dimensões de universalidade, particularidade e singularidade na análise dos fenômenos presentes no contexto da prática profissional". (IAMAMOTO, op.cit.:191) Ou seja, a questão aqui, parte do equívoco de se pensar que o método é aplicável na prática. $\mathrm{Na}$ realidade, o método deve ser apropriado de modo que possamos, a partir dele, analisar os processos macrossociais que interferem na vida em sociedade e de que forma os sujeitos a vivenciam. Ultrapassar o campo da abstração para as singularidades presentes no exercício profissional significa a absorção de uma realidade específica através da pesquisa científica levando em conta os processos macros que a produzem.

Articulada à questão anterior acima citada, Iamamoto menciona que no âmbito do ensino, encontra-se "o vazio sobre as estratégias, táticas e o arsenal de instrumentalização para o agir profissional". A autora destaca a produção de Faleiros - um dos autores que mais tem investido nesse aspecto. Os obstáculos para o direcionamento desses "vazios" tem resultado na "renovação" do tecnicismo, como também, na dificuldade de se operar objetivamente, "as intencionalidades e projetos veiculados pelo discurso profissional" (op.cit.: 192).

Por fim, a chave que engloba as últimas questões aqui explicitadas, encontra-se articulada à outra problemática: "o tratamento da prática profissional do assistente social". Para Iamamoto, alguns dos obstáculos da formação profisisonal encontram-se

nas políticas de estágio/pesquisa, no ensino da prática, no precário desenvolvimento de relações acadêmicas entre os centros de formação e as instituições do mercado de trabalho, que oferecem campos de treinamento profissional, na rede de intercâmbios entre Universidade e o meio profissional. (op.cit.:193)
A autora cita dois aspectos fundamentais que encaminham tais dilemas. $\mathrm{O}$ primeiro encontra-se relacionado à necessidade de se apropriar mais rigorosamente do arsenal teórico-metodológico que repercute sobre a formação profissional, sobretudo por parte dos docentes, ultrapassando a simples reprodução das concepções à apreensão da lógica de construção das explicações da vida em sociedade. Certamente, essa condição iluminará as análises das situações cotidianas vivenciadas pelos assistentes sociais no exercício profissional.

E, segundo, o encaminhamento desses dilemas exige uma criteriosa pesquisa sobre as questões que se refletem no exercício profissional e dos processos que as produzem, como condição para preencher a lacuna no campo das mediações entre a teoria e prática. Para Iamamoto, as mediações são reveladas na pesquisa sobre a realidade e na descoberta de situações específicas confrontadas pelo assistente social. Abranger tais questões é, sem dúvida, não perder de vista "os processos macroscópicos que as geram e as recriam e, ao mesmo tempo, de como são experimentadas e vivenciadas pelos sujeitos nelas envolvidos". (op.cit.:194)

Não menos importante encontra-se o debate sobre os novos espaços de trabalho do Serviço Social. Certamente, a sintonia entre formação profissional e mercado de trabalho não se traduz na mera "formatação" às exigências do mercado, como se a formação universitária tivesse que subjugar aos ditames neoliberais regulares do mercado. Concordamos com Iamamoto quando diz que a exigência é "de uma formação profissional sintonizada com o mercado de trabalho e, ao mesmo tempo, dotada de um distanciamento crítico do mesmo". (op. cit.:171)

Essa sintonia deve ser capaz de identificar as demandas que se manifestam no âmbito estatal e empresarial, a partir das tendências dominantes do processo de acumulação capitalista e das políticas governamentais que impulsionam a sua realização. É preciso também, identificar o que está por detrás dessas tendências. Ou, nos termos de Iamamoto, "apreender as contratendências desse processo: ver o reverso da medalha da crise, identificando como tais contratendências se refratam no mercado profissional de trabalho". (op.cit.:171-172)

Inscrita na divisão sócio-técnica 
do trabalho, a reprodução do Serviço Social dependerá da sua capacidade de responder às necessidades sociais, de onde origina a sua demanda. Como trabalhador assalariado, o assistente social necessita vender a sua força de trabalho especializada no mercado profissional de trabalho. Essa força de trabalho obterá valor de troca, caso comprove o seu valor de uso no mercado.

Para Iamamoto (op.cit.), parte daí a necessidade de uma reformulação no projeto de formação profissional afinado com o novo perfil da demanda profissional no mercado de trabalho com vistas a qualificar profissionais que confirmem sua necessidade e, também, respondam criticamente os desafios engendrados pelas mudanças que refletem nas esferas da produção e do Estado, repercutindo incisivamente na conformação das classes sociais.

Para Netto (1996), quando se leva em conta os aspectos estruturais no Brasil, verifica-se que a demanda objetiva de uma profissão como o Serviço Social não tende a se contrair. $\mathrm{O}$ autor afirma que a dinâmica das relações capitalistas no marco nacional garante espaços aos assistentes sociais. Mas, o autor esclarece que, as distintas hegemonias políticas podem direcionar distintamente o processo social brasileiro e, assim, demandar distintas perspectivas e estratégias de ação profissional.

Na realidade, o autor ressalta que isso é apenas possibilidade objetiva, colocada no cenário brasileiro e pela particularidade que o Serviço Social adquiriu na sua trajetória histórica. Essa conversão será possível a partir da capacidade de resposta profissional do assistente social à demanda e do grau de "compatibilidade com a hegemonia política que vier a afirmarse e/ou da sua funcionalidade em relação às eventuais 'contra-hegemonias' que puderem se desenvolver". Se, não houver respostas qualificadas às demandas, "o Serviço Social pode muito bem definhar e tornar-se um exercício profissional residual”. (NETTO, op.cit.:115)

Traçadas as observações iniciais, o que pretendemos agora é expor o debate em torno das mudanças no mercado profissional de trabalho. Segundo informações de Iamamoto $(2001)^{2}$, o setor público continua sendo o grande empregador de assistentes sociais, sendo que a esfera estadual e municipal são as que mais empregam.

Ainda que o setor público se apresente como o maior empregador de assistentes sociais, o quadro de pessoal vem sofrendo os efeitos da "Reforma do Estado" no enxugamento e na flexibilização dos contratos, representado pela redução dos concursos públicos, demissão do quadro de funcionários sem estabilidade, contenção de salário, entre outros. Outro dado importante é a terceirização na contratação dos assistentes sociais nas cooperativas, fundações, e entidades filantrópicas, através dos quais os Órgãos Públicos buscam a contratação. (IAMAMOTO, op.cit.; SERRA, 2000)

No que se refere aos espaços de trabalho, a Seguridade Social(Previdência, Saúde e Assistência Social), reconhecida como política pública pela Constituição Federal de 1988, compõe um espaço privilegiado de trabalho para o Serviço Social. Em decorrência do processo de implementação do Sistema Único de Saúde (SUS), a área de saúde apresenta uma grande concentração de assistentes sociais, seguida da assistência social e previdência. (IAMAMOTO, op.cit.)

Quanto à assistência social, abriram-se novas possibilidades de intervenção motivadas pela municipalização das políticas públicas. Para Iamamoto (op.cit.), a implementação dos conselhos municipais; a capacitação de conselheiros; elaboração e gerenciamento de projetos sociais; a organização e mobilização popular em práticas de orçamento participativo, são algumas das fontes de diversificação de demandas para o trabalho do assistente social.

Ainda no campo da assistência social, incluímos aqui, a implementação do Sistema Único de Assistência social (SUAS) a partir de outubro de 2004, que, certamente abriu novos espaços de trabalho para o assistente social, com a instalação dos Centros de Referências de Assistência Social (CRAS) nos municípios.

Iamamoto (op.cit.) diz ainda que, a "gestão social pública" ou "gerência pública" são expressões atuais e merecem destaque, porque abrem espaço para um conjunto de especializações profissionais. E para cumprir o exercício de funções requeridas no campo da gestão de políticas sociais públicas, exigemse níveis de aperfeiçoamento na formação profissional, permitindo que o assistente social concorra em igualdade de condições com outros profissionais como sociólogos, cientistas políticos, pedagogos, etc.

A "filantropia empresarial" é um setor em crescimento e, representa um novo modelo 
de ação social nas quais as empresas "cidadãs" investem no campo social através de projetos comunitários compreendidos como de interesse público. Esse setor constitui, também, espaço de trabalho para os assistentes sociais. Iamamoto (op.cit.) ao analisar esse setor, observa que a lógica que move os projetos e programas sociais não é de interesse público e sim de interesse privado. A área de Recursos Humanos tem absorvido o trabalho do assistente social para atuar em programas de prevenção de acidentes, saúde do trabalhador, círculos de qualidades e tantos outros programas oferecidos pelas organizações privadas em busca de atender a nova lógica gerencial produtiva.

E, as exigências para ingressar na esfera empresarial não se limitam ao campo de conhecimentos: é necessário que se tenham qualidades e habilidades pessoais, tais como experiência, criatividade, capacidade para negociar, fluência verbal, o domínio não só da língua inglesa, como o espanhol, informática, entre outros.

$\mathrm{Na}$ perspectiva estatal, observa-se a necessidade de superar uma administração pública e burocrática por um modelo gerencial, eficaz e de controle de resultados, acentuando a redução dos custos, da qualidade, e da produtividade nos serviços oferecidos ao cidadão. A "Reforma do Estado" propõe novas relações entre Estado e Sociedade, onde o governo se desresponsabiliza diretamente pelo desenvolvimento social e econômico e passa a promover e regular esse desenvolvimento, transferindo as responsabilidades para o setor privado, as ações que possam ser gerenciadas pelo mercado. (IAMAMOTO, op.cit.)

Para Iamamoto (op.cit.), tais aspectos encontram-se traduzidos na privatização das empresas estatais e na "publicização" dos serviços de saúde, educação e cultura, possibilitando um abandono do Estado no papel de executor desses serviços ${ }^{3}$.

Nesse sentido, o Estado preocupase em fortalecer e regulamentar o nomeado "Terceiro Setor"4 para gerenciar e executar as políticas sociais, refletindo nas condições de trabalho e mercado de trabalho especializado.

Como observa Iamamoto (op.cit.), a transferência de responsabilidades para a sociedade civil vem se traduzindo em um crescimento de parcerias do Estado com as ONGs que têm como proposta de trabalho, elaborar, gerenciar e avaliar programas sociais direcionados à área da criança e adolescente, educação, saúde, família, etc..., limitando assim, a universalização dos serviços públicos.

Tudo isso evidencia, uma nítida modificação no conjunto das novas requisições profissionais apresentadas ao Serviço Social. Serra (2000) em sua pesquisa sobre a crise do Serviço Social, nos anos de 1990, analisou as tendências do mercado de trabalho público e privado, assim como, a função do assistente social e, a partir daí, delimitou algumas preocupações acadêmicas no que se refere aos rumos da profissão no atual quadro ${ }^{5}$.

Uma das preocupações da autora diz respeito aos avanços teórico-metodológicos e a pesquisa. Segundo Serra (op.cit.), tais avanços são privativos de uma elite da profissão que circunscreve os espaços acadêmicos. Há que se pensar quais seriam as reais chances de qualificar o contingente profissional, inserido no mercado de trabalho ou aguardando um posto de trabalho.

E, vai mais além. Na sua perspectiva de análise, a qualificação é extensiva à profissão como uma necessidade generalizada (mesmo ao segmento minoritário mais qualificado). Isso significa dizer que, a profissão não está instrumentalizada para responder as requisições do mercado atual, nem para disputar o mercado com outros profissionais, sem que não se perspective um processo interno rigoroso de capacitação para atender criticamente as exigências do mercado.

Evidentemente, Serra (op.cit.) reconhece que o avanço teórico dos anos de 1980 para cá, imprimiu à profissão um status intelectual de competência acadêmica e, na interlocução com outras áreas sociais. No entanto, suas indicações, referem-se sempre ao conjunto da categoria profissional, justificando assim, a exposição acima. A autora propõe uma capacitação profissional integrada com outros componentes: especialização, habilitações, níveis de ação e áreas de atuação. Ressalta que, a questão da especialização, primeiro elemento da capacitação profissional, deveria ser objeto de enfrentamento nos debates profissionais, um dos caminhos essenciais atualmente.

De fato, a especialização é um prérequisito básico para atender às exigências de um mercado de trabalho altamente competitivo, onde a graduação não significa mais uma exigência primária. Serra observa que é um equívoco persistir na visão de que a especialização 
profissional - temática desprezada no contexto do "Movimento de Reconceituaçao" - implica recortar a realidade. Considerando a perspectiva histórico-crítica como viés teórico-metodológico da adesão profissional, o que se percebe é "uma complementaridade entre a base generalista e a especialização". (op.cit.:169)

O segundo elemento da capacitação profissional são as habilitações - requisito indispensável para compor a formação profissional em todas as áreas. As exigências do mercado atual frente às transformações do "mundo do trabalho" demandam respostas mais eficazes e efetivas em todas as profissões. Assim, deve-se requisitar um profissional de articulação, propositivo, formulador e gestor, capaz de apresentar respostas à "questão social”, contrárias as de cunho fragmentado e setorialista que impele a agenda neoliberal.

De acordo com Serra, para se concretizar as especializações e o treinamento dessas habilidades, faz-se necessário, o terceiro elemento da capacitação profissional, que são os níveis de ação. Aqui, devem ser consideradas como perspectiva de intervenção a "execução, gestão, assessoria, consultoria e supervisão", como níveis diferenciados para reunir as orientações de capacitação, para atuar nas instituições públicas e privadas e/ou no exercício profissional autônomo. A autora reforça a importância desse treinamento (pontual e específico) desenvolver-se de forma articulada e integrada à base generalista macroscópica. (op . cit::172)

O quarto elemento da capacitação profissional são as áreas de atuação do Serviço Social. Serra (op.cit.) aponta à necessidade de se interligar, num exame minucioso, as áreas de atuação com as políticas sociais atuais. Em outras palavras, é importante entender porque algumas áreas de atuação ampliam ou sofrem retração nos postos de trabalho. Isso implica uma compreensão mais ampla dos processos políticoeconômicos e institucionais que modificam a realidade de determinada área de trabalho.

Em síntese, pensamos que para enfrentar o mercado de trabalho nos marcos das "transformações societárias" (Netto, 1996), é necessário atentar para os novos rumos que a categoria profissional deverá tomar na direção de instrumentalizar o seu trabalho com comprometimento e competência, para responder as demandas sociais, ampliando as bases de legitimidade do Serviço Social.
Entendemos que esse quadro sóciohistórico não nos permite recusar o exercício profissional em determinadas áreas de trabalho que se abrem em decorrência da atual conjuntura. Devemos sim, ocupar esses espaços de trabalho com competência crítica, contribuindo para desvelar aos usuários as estratégias políticas que se inscrevem nas instâncias públicas e privadas, com vistas a descaracterizar os traços conservadores e burocráticos presentes no discurso estatal.

Isso requer, a nosso ver, uma ampla discussão em âmbito acadêmico, juntamente com os profissionais envolvidos nas mais diversas áreas de trabalho em que atuam. Não temos dúvidas que a profissão tem um compromisso com os usuários do Serviço Social, compromisso inscrito no Código de Ética Profissional e estendendo ao projeto ético-político da profissão que vai além da "defesa" dos usuários - é um projeto societário que contesta a ordem social vigente, e aposta na (re) construção de uma nova ordem social.

\section{As atuais tendências do mercado de trabalho do assistente social a partir de um estudo realizado com os alunos egressos do Curso de Serviço Social - UniFOA}

Ainda que de forma concisa, pensamos que o debate que ora apresentamos sustentará os dados sobre a pesquisa realizada com os alunos egressos do Curso de Serviço Social - UniFOA. E mais que isso, esse debate reforça a nossa preocupação acadêmica de revelar aos alunos e profissionais do Serviço Social os desafios e dilemas da formação profissional frente às tendências do mercado profissional de trabalho.

O curso em Serviço Social do Centro Universitário de Volta Redonda - UniFOA, teve início no ano de 2001, e hoje conta com quatro turmas já formadas para o mercado de trabalho e, oito turmas em processo de formação. Vale destacar que, na região Médio Paraíba, é o único curso em Serviço Social reconhecido pelo MEC (Portaria MEC no. 3.142/05 de 13/09/05).

Tendo como eixo central de reflexão, atribuir visibilidade ao mercado profissional de trabalho, entre os dias 18 e 20 de julho de 2007 , entrevistamos 29 alunos representando $48 \%$ do total de alunos graduados até fevereiro de $2007^{6}$. A entrevista estruturada com perguntas fechadas foi realizada através de uma comunicação 
telefônica, quando solicitamos aos alunos egressos que respondessem a algumas questões sobre a inserção no mercado de trabalho.

Anterior a apresentação dos dados sobre a inserção no mercado de trabalho, examinaremos algumas outras questões que se estenderam nessa pesquisa. A nossa primeira exposição diz respeito ao perfil socioeconômico dos entrevistados. Com base na amostra pesquisada, identificamos que, $45 \%$ dos entrevistados encontram-se na faixa etária entre 20 a 30 anos; $38 \%$ entre 41 a 50 anos; e 17\% entre 31 a 40 anos. Notamos que, a maioria dos entrevistados encontra-se na faixa etária entre 20 a 30 anos, demonstrando uma inserção imediatamente após a conclusão do Ensino Médio para a graduação.

Por serem jovens, identificamos que, a maioria (34\%) dos entrevistados mora com os pais, ou seja, com a família de origem; seguidos de $31 \%$ de famílias nucleares; $17 \%$ vivem só; e os demais $17 \%$ são famílias monoparentais. Os dados sobre a composição familiar dos entrevistados assumem alguns aspectos amplamente discutidos nos circuitos acadêmicos sobre os novos arranjos familiares presentes na contemporaneidade. O debate atual aponta para uma redução das famílias nucleares, e o surgimento de novas configurações familiares delineadas a partir de mudanças de ordem econômica, social e cultural nos anos 1950.

(ALENCAR, 2004; MIOTO, 1997)

Sobre a renda mensal familiar dos entrevistados, informamos o seguinte quadro: $45 \%$ apresentam uma renda familiar mensal de 4 a 6 salários mínimos; seguidos de $35 \%$ acima de 10 salários mínimos; $10 \%$ de 1 a 3 salários mínimos; e os demais $(10 \%)$ de 7 a 10 salários mínimos.

Em relação ao sexo, $90 \%$ são pessoas do sexo feminino; e os demais (10\%) são pessoas do sexo masculino. Aqui, cabe apontar o nítido recorte de gênero que, marca a história da profissão.

De fato, Iamamoto (2001) ao refletir sobre o perfil do assistente social ${ }^{7}$, indica que o contingente profissional hoje origina de segmentos médios pauperizados, apresentando um nítido recorte de gênero. Ou seja, "uma categoria profissional predominantemente feminina, uma profissão tradicionalmente de mulheres e, para mulheres". Essa condição feminina é uma das marcas da profissão, ainda que consideremos o contingente masculino de assistentes sociais, expressão que constitui a minoria do contingente profissional.

A autora ressalta, ainda, que esse perfil absorve tanto a imagem social da mulher quanto às discriminações por ela vivenciadas no mercado de trabalho. Tais discriminações passam pela diferenciação salarial em relação ao homem, os níveis de formação em relação às exigências tecnológicas, maior índice de desemprego, etc.

Os entrevistados, em sua maioria (83\%) trabalharam durante o curso, seguidos de $17 \%$ que não trabalharam. É bom lembrar que o Curso de Serviço Social do UniFOA é um curso noturno. Esse aspecto de curso noturno proporciona $\mathrm{o}$ acesso às pessoas que se encontram no mercado de trabalho de ingressarem no circuito universitário. Dos entrevistados que trabalharam durante o curso, informamos que as áreas de atuação citadas com mais freqüência foram, o comércio, instituição de ensino, organizações privadas e públicas, estágios extracurriculares, entre outros.

No decorrer do curso, 62\% dos entrevistados não receberam nenhum tipo de bolsa de estudo ou financiamento escolar; 24\% estudaram através do Financiamento Escolar (FIES); e 14\% receberam algum tipo de bolsa de estudo, seja através de descontos na mensalidade, seja pela isenção total da mensalidade do referido curso.

Quanto à formação profissional, observamos, através dos dados coletados, que a maioria (72\%) dos entrevistados não participou de projetos de iniciação científica existentes no curso de Serviço Social; os demais (28\%) afirmaram que participaram de algum projeto de iniciação científica.

Esses dados podem ser justificados à medida que o curso de Serviço Social da referida universidade teve início em 2001, e por isso, caminha na estruturação de projetos de pesquisa e extensão. Ressaltamos, também, que o Centro Universitário de Volta Redonda - UniFOA, formulou seu convênio com Instituição de Fomento a Pesquisa em 2004. Atualmente, o curso conta com vários projetos de pesquisa desenvolvidos e em desenvolvimento nas mais diversas linhas de pesquisa em Serviço Social, envolvendo professores e alunos, demonstrando o compromisso do curso com a pesquisa social.

O curso de Serviço Social no UniFOA, estabelece como linhas de pesquisa, os seguintes temas: a) Estado, Sociedade e Políticas Sociais; 
b) Interdisciplinaridade e Trabalho Profissional,

c) Práticas Sociais e Cidadania; d) Produção de Subjetividade e Saberes, e) Trabalho e Sociabilidade. Atualmente, os projetos em desenvolvimento são:

\section{- Estado, Sociedade e Políticas}

Sociais (nomes dos projetos: "Planejamento Familiar e a prevenção de doenças sexualmente transmissíveis e AIDS no município de Volta Redonda", "Políticas Sociais para a Promoção da Igualdade Racial: a luta do movimento negro na região Sul-Fluminense");

\section{- Interdisciplinaridade e Trabalho}

Profissional (nomes dos projetos: "Código de ética do assistente social: instrumento Norteador da intervenção profissional? Reflexões sobre sua (não) aplicabilidade no cotidiano da prática", "O trabalho do assistente social supervisor de estágios na saúde: uma análise de possibilidades, limites e tendências");

\section{- Práticas Sociais e Cidadania}

(nomes dos projetos: "Direito e Cidadania: os impactos da interdição no cotidiano de vida dos portadores de transtornos mentais", "As Relações de Trabalho dos Descendentes diretos de escravos ainda residentes nos remanescentes de quilombos: São Jose da Serra (Valença/RJ) e Campinho de Independência (Paraty/RJ)".

Concordamos com Iamamoto quando observaque apesquisa tem umpapel fundamental no processo de formação profissional do assistente social, atividade pela qual se solidifica os laços existentes entre o ensino e a realidade social. O Serviço Social é uma profissão que apresenta uma dimensão prático-interventiva e, supõe um acervo teórico-metodológico advindo das ciências social e humana e pela teoria social crítica para compreensão da vida social. Entretanto, se mostram insuficientes se não houver uma articulação com a pesquisa da realidade, ou seja, "dos fenômenos históricos particulares que são objetos do conhecimento e da ação do assistente social". (op.cit.:273)

Para imprimir qualidade à formação profissional, observamos que os entrevistados investiram em atividades extracurriculares tais como: seminários $(100 \%)$, palestras $(100 \%)$, cursos $(86 \%)$, e congressos $(69 \%)$ nas mais diversas áreas de estudo do Serviço Social.

Esses dados se mostram relevantes à medida que as exigências do mercado profissional de trabalho requerem cada vez mais uma formação profissional qualificada. Notamos que nessa amostra pesquisada, houve um investimento tanto do aluno quanto da universidade, uma vez que foram oferecidos aos alunos espaços de participação nas mais diversas atividades extracurriculares.

No que se refere às áreas de estágios curriculares dos entrevistados, a pesquisa identificou que $35 \%$ na a área da assistência social, seguidos de $35 \%$ na área de sujeitos sociais e cidadania (criança e adolescente, idoso, violência contra a mulher, e pessoas com deficiência, empresa), e 30\% na área da saúde hospitalar e programas de saúde.

Sobre o estágio curricular, consta no "Projeto de Estágio Curricular do Curso de Serviço Social - UniFOA" (2003), que o estágio é uma atividade curricular obrigatória, e se configura a partir da inserção do aluno no espaço sócio-ocupacional, com vistas à capacitação para o trabalho profissional. Essa é uma das diretrizes curriculares de Serviço Social, que, juntamente com a ABESS, considera o Estágio Supervisionado

uma atividade curricular obrigatória que se configura a partir da inserção do aluno no espaço sócio-institucional, objetivando capacitá-lo para o exercício profissional, o que pressupõe supervisão sistemática. Esta supervisão deve ser feita pelo professor supervisor e pelo profissional do campo, através da reflexão, acompanhamento e sistematização, com base em planos de estágios elaborado em conjunto pelas unidades de ensino e organizações que oferecem estágios. (2003:5)

O Estágio Supervisionado em Serviço Social do referido curso exige que as instituições conveniadas para estágio curricular tenham em seus quadros um assistente social registrado no Conselho Regional para que possa realizar o acompanhamento ao aluno estagiário. $\mathrm{O}$ estagiário dispõe de oficinas de supervisão que contemplam várias temáticas que envolvem o trabalho do assistente social. Cada oficina de supervisão conta com um professor afinado com o debate contemporâneo demandado dos estágios específicos. Atualmente, o curso conta com cinco oficinas de supervisão abrangendo os seguintes campos de estágio: Oficina de Assistência; Oficina 1 de Saúde (saúde hospitalar) e Oficina 2 de Saúde (Programas de Saúde); Oficina 1 de Sujeitos Sociais e Cidadania (empresa, pessoas com deficiência e campo sócio-jurídico) e Oficina 2 de Sujeitos Sociais e Cidadania (criança e adolescente, mulher, idoso). 
Ainda contemplando o estágio curricular, perguntamos aos entrevistados se o Trabalho de Conclusão de Curso (TCC) privilegiou estudos relacionados a partir do campo de estágio. Assim, através dos dados da pesquisa, observamos que, a grande maioria (79\%) dos alunos assumiu o compromisso de realizar um estudo a partir de questões vivenciadas através do estágio curricular; seguidos de $29 \%$ de alunos que realizaram estudos através de questões externas ao campo de estágio.

De fato, sugere-se que o Estágio Supervisionado apresente como produto acadêmico o Trabalho de Conclusão de Curso (TCC). O TCC é um trabalho científico exigido pelas diretrizes curriculares para obtenção do diploma de graduação em Serviço Social. Nesse trabalho, o aluno deve ser capaz de sistematizar o seu conhecimento,

como resultado de um processo investigativo, a partir de uma indagação teórica, preferencialmente provocada pela prática de estágio. Ou seja, trata-se da problematização, teoricamente fundamentada, de um tema colhido na experiência de estágio ou de pesquisa. (IAMAMOTO, op.cit.:286)

Sobre a inserção no mercado de trabalho, a maioria (79\%) já se encontra inserido nos espaços sócio-institucionais nos vários municípios que compõem a região Médio Paraíba $^{8}$, com um acentuado predomínio para o município de Volta Redonda. Os demais (21\%) entrevistados encontram-se desempregados ou ocupando outras funções no mercado de trabalho que diferem da formação profissional.

Analisando os dados sobre a inserção no mercado de trabalho, nota-se que houve uma absorção significativa de assistentes sociais, já que a maioria (79\%) dos entrevistados compõe, atualmente, o quadro de profissionais do Serviço Social nas diversas áreas de trabalho. Alguns, inclusive, possuem mais de um trabalho. Essa possibilidade se dá (ou não) através da carga horária de trabalho, que em algumas instituições (públicas ou privadas) soma 20 horas semanais.

Nessa amostra pesquisada, observamos que a inserção no mercado de trabalho abrangeu uma fatia significativa do âmbito público municipal. Do total de entrevistados que trabalham, 91\% encontram-se inseridos no âmbito público municipal, sendo que a maioria trabalha na área da assistência social, ocupando cargos como: assistentes sociais, coordenadores técnicos dos CRAS, coordenadores do Programa Bolsa Família, Coordenadores do Programa Sentinela, Secretário Municipal da Assistência Social, chefe de divisão na Secretaria de Assistência Social. Apenas 9\% dos entrevistados encontram-se no âmbito privado.

Pois bem, a tentativa agora é refletir sobre os espaços sócio-ocupacionais desses trabalhadores especializados do mercado de trabalho. Sem dúvida, os números aqui relevam um grau acentuado (91\%) de assistentes sociais no âmbito público municipal na área da assistência social demonstrando que o Serviço Social legitima-se até os dias atuais, como uma profissão institucionalizada, com maior incidência de contratação no setor público. Acontece que, dentro do setor público, observase uma evidência para a inserção de trabalho nos municípios. Aqui apresentamos duas hipóteses que podem justificar esses dados.

A primeira hipótese é a de que a descentralização das políticas sociais, em especial a da assistência tem contribuído para o aumento do quadro de assistentes sociais no município. Isso porque um dos desdobramentos desse debate aponta para uma proposição explícita contida na LOAS sobre o reordenamento das funções entre os três níveis de governo: 1) o município deve ser o lócus privilegiado da execução dos serviços assistenciais (prestação direta de serviços e a gestão dos convênios com entidades assistenciais); 2) cabe ao Estado um papel acessório, estes deveriam atuar nas situações em que os municípios não pudessem desempenhar a contento suas funções; e 3) a política de assistência deve continuar a ser implementada através de convênios com entidades filantrópicas privadas (moeda de troca eleitoral) que passariam a ser geridos (contratados, pagos e fiscalizados), pelos municípios, ainda que financiados pelo governo federal. (ARRETCHE, 2000)

A segunda hipótese - intimamente relacionada com a primeira - é a de que a implementação do SUAS (aprovado em 2004), impulsionou a demanda por profissionais do Serviço Social para atuarem em equipes interdisciplinares nos CRAS e nas modalidades de programas sociais ${ }^{9}$ que envolvem esta política.

É preciso reconhecer que a construção e consolidação do SUAS, adota um regime geral de gestão e normatiza a gestão da Política de Assistência e, apresenta um "sistema 
descentralizado, participativo e integrado, compreendendo os serviços assistenciais de órgãos públicos e entidades não-governamentais, tendo a família como foco de atenção e o território como base da organização". (VASCONCELOS \& MORGADO, 2005)

Gostaríamos de registrar aqui, algumas observações dos entrevistados quanto às formas de contratação salarial existentes atualmente. É que, durante a entrevista, alguns entrevistados questionaram se a pesquisa não iria abranger as condições de trabalho do assistente social. Na realidade, as mudanças no "mundo do trabalho" provocadas pela crise econômica que data os anos 1970, repercutem mundialmente nas formas de reestruturação produtiva; alterando as profissões, as áreas de intervenção e condições de trabalho, as perspectivas teóricas, funções sociais, etc. (ANTUNES, 1995; HARVEY, 1989; IAMAMOTO, 2001)

Não dispomos de dados concretos para levantar aqui uma hipótese, mas com base no debate presenteno circuito acadêmico, sugerimos que o mercado profissional de trabalho do assistente social-inclusive da amostra pesquisada - sofre os impactos diretos das transformações em curso na realidade brasileira, através da eliminação e/ou redução dos postos de trabalho no âmbito público e privado, e da flexibilização das relações de trabalho expressa nos contratos temporários, conforme determinações da agenda neoliberal. Evidentemente, frente à precariedade no "mundo do trabalho" os salários sofrem uma queda, o que pode justificar a "opção" por dois empregos para complementar o baixo salário. (SERRA, 2000)

A qualificação profissional, dado imprescindível para o enfrentamento do mercado profissional de trabalho no atual contexto histórico, também foi motivo de questionamento. Por isso, perguntamos aos entrevistados sobre o interesse em realizar uma Pós-graduação, e a grande maioria (93\%) demonstrou interesse nos mais diversos campos, a saber: política social, terapia de família, docência, empresa, saúde da família, mestrado e direito.

Mas, é preciso ressaltar que do total de entrevistados, 59\% já se encontram nos cursos de pós-graduação nas seguintes áreas: gerontologia/geriatria, docência, mestrado, empresa, gestão em Recursos Humanos, gestão social, gestão e administração pública, saúde da família. Os demais (41\%) não se encontram em nenhum curso de pós-graduação.
Conforme já discutido no percurso teórico deste estudo, reafirmamos que a capacitaçãoprofissional tem se apresentado como condição necessária para compor a qualificação profissional do assistente social. Essa questão tem sido discutida, sobretudo nas pesquisas sobre o mercado de trabalho do Serviço Social. Esse componente, sem dúvida, contribuirá para a "própria sobrevivência do Serviço Social", além de assegurar aos usuários, serviços pautados nos fundamentos ético-políticos, técnico-operativos e teórico-metodológicos amplamente discutidos no processo de formação profissional. (SERRA, 2000, SILVA apud IAMAMOTO, 2001)

Enfim, o processo de formação profissional é hoje, um grande desafio que deve ser enfrentado pelos docentes/discentes preocupados com a qualidade do trabalho que serão oferecidos à sociedade. Nesse sentido, cabe ressaltar que as reflexões que ora apresentamos, partiu da preocupação acadêmica não apenas de revelar o atual mercado de trabalho, mas também de contribuir para o debate sobre o Serviço Social no bojo das transformações em curso que afetam o "mundo do trabalho" a partir de uma realidade especifica.

Como qualquer profissão inscrita na divisão sócio-técnica do trabalho, o Serviço Social na cena contemporânea sofre os impactos desse quadro sócio-histórico e, enfrenta o desafio de (re)construir coletivamente a formação profissional e o trabalho profissional, uma vez que o Código de Ética Profissional privilegia valores como

a ampliação e consolidação da cidadania e

a garantia dos direitos sociais; a defesa do aprofundamento da democracia, enquanto socialização da participação política e da riqueza socialmente produzida; a defesa da eqüidade e da justiça social na perspectiva de universalidade de acesso aos bens e serviços relativos aos programas e políticas sociais; o compromisso com a qualidade dos serviços prestados à população e com o aprimoramento intelectual. (COLETÂNEA DE LEIS E RESOLUÇÕES - CRESS 7ª - RJ:13-14)

É nesta direção que se inscreve a proposta curricular do referido curso. Isso implica o compromisso da academia, não apenas de formar profissionais, mas de colocar e discutir as problemáticas que permeiam a sociedade contemporânea, para que possam 
pensar criticamente e com competência sobre as múltiplas determinações e manifestações da "questão social", objeto de seu trabalho. Esperamos que este estudo possa, de fato, somarse a outros estudos já realizados e, estimular espaços de discussão nos canais que interagem com a categoria profissional.

\section{Notas}

${ }^{1}$ Para Faleiros (1997), a "prática higienista" é fruto de mudanças no plano científico provocado pelo avanço das pesquisas médico-sociais, psicossociais, biológicas e sociais. Portanto, predomina-se nesse período, o pensamento de biologização da sociedade, associado a uma forte influência da moral e da ordem de cunho religioso e conservador.

${ }^{2}$ Esta exposição de Iamamoto (2001) teve como base, uma pesquisa realizada pela Pontifícia Universidade Católica de São Paulo (PUC-SP) e Conselho Regional de Serviço Social - CRESS/ $9^{a}$ Região, sob coordenação de Silva, sobre o mercado de trabalho profissional no Estado de São Paulo.

3 Neste sentido, a "publicização" refere-se a descentralização, para o setor público não estatal, da execução de serviços que não comprometam o Estado, mas que por ele, são subsidiados. Exemplos: a educação, a saúde, a cultura e a pesquisa científica. (IAMAMOTO, 2001:121)

${ }^{4} \mathrm{O}$ “Terceiro Setor" é um termo importado que, na atualidade começa a ser utilizado na sociedade brasileira para indicar fenômenos e questões que se referem a um universo de organizações da sociedade civil. (LANDIM., 1999:61)

${ }^{5}$ Tais indicações têm como base, a análise de dados empíricos da realidade do Serviço Social no Rio de Janeiro. Cf. Capítulo III - O Serviço Social no Rio de Janeiro na crise do Estado brasileiro e em face do projeto neoliberal In Crise da Materialidade no Serviço Social. (SERRA, 2000)

${ }^{6}$ A última graduação ocorreu em julho de 2007 e, por isso, não foi computado no total de alunos egressos entrevistados.

${ }^{7}$ Netto ao analisar o perfil do assistente social, em especial, do alunado, indica também uma clara "mudança no perfil socioeconômico, cada vez mais recrutado em estratos médio-baixos e baixo das camadas urbanas". (1996:110)

${ }^{8}$ Compõem a região Médio Paraíba as seguintes cidades: Porto Real, Resende, Quatis, Barra
Mansa, Volta Redonda, Rio Claro, Piraí, Pinheiral, Barra do Piraí, Valença, Rio das Flores, Vassouras e Itatiaia.

9 A título de informação, além dos CRAS, as modalidades de programas sociais são: Programa de Atenção Integral à Família (PAIF); Programa de Inclusão Produtiva e Projetos de Enfrentamento à Pobreza; Centro de Convivência de Idosos; Serviços para crianças de 0 a 6 anos; Serviços sócio-educativos para crianças, adolescentes e jovens, na faixa de 6 a 24 anos; Centros de informação e educação para o trabalho, para jovens e adultos. (VASCONCELOS \& MORGADO, 2005)

\section{Referências}

ALENCAR, Mônica Maria Torres. Transformações econômicas e sociais no Brasil dos anos 1990 e seu impacto no âmbito da família. In Política Social, Família e Juventude: uma questão de direitos. São Paulo: Cortez, p. 61-78, 2004.

ANTUNES, Ricardo. Adeus ao Trabalho? Ensaio sobre as Metamorfoses e a centralidade do mundo do trabalho, São Paulo: Cortez, 1995.

ARRETCHE, Marta. "Descentralização da Política Federal de Assistência Social" In Estado Federativo e Políticas Sociais: determinantes da descentralização. Rio de Janeiro/ São Paulo: Revan/ Fapesp, 2000.

BRASIL - MANUAL INFORMATIVO SISTEMA ÚNICO DE ASSISTÊNCIA SOCIAL (SUAS) - Secretaria Nacional de Assistência Social - Ministério do Desenvolvimento Social e Combate à Fome, 2004.

Coletânea de Leis e Resoluções - CRESS $7^{\circ}$ Região - Rio de Janeiro, 2001.

FALEIROS, Vicente de Paula. Estratégias em Serviço Social, São Paulo: Cortez, 1997.

HARVEY, David. A condição pós-moderna - uma pesquisa sobre as origens da mudança cultural. São Paulo: Loyola, 1989.

IAMAMOTO, Marilda Villela. O Serviço Social 
na Contemporaneidade: trabalho e formação profissional, 4aed., São Paulo: Cortez, 2001.

IAMAMOTO, Marilda Villela \& CARVALHO, Raul. Relações Sociais e Serviço Social no Brasil: esboço de uma interpretação históricometodológica. $15^{\mathrm{a}}$ ed., São Paulo: Cortez; Celats, 2003.

LANDIM, Leilah. "Notas em torno do terceiro setor e outras expressões estratégicas" In O Social em Questão, no 4, Ano 3, PUC, Rio de Janeiro, 1999.

MELO, Magnólia. A influência do pensamento Marxista no Serviço Social brasileiro a partir da década de 80. Fonte:http://pessoal.sercomtel. com.br/colman, Outubro de 2001.

MIOTO, Regina Célia Tamaso. "Família e Serviço Social". In Serviço Social \& Sociedade, São Paulo: Cortez, no 55, p. 114-128, 1997.

NETTO, José Paulo. “Transformações societárias e Serviço Social” In Serviço Social \& Sociedade, São Paulo: Cortez, nº50, Ano XVII, p. 87-131, 1996.

"A construção do projeto éticopolítico contemporâneo" In Capacitação em Serviço Social e Política Social. Módulo 1 - Cead/ABEPSS/ CFESS, Brasília, 1999.

Ditadura e Serviço Social: uma análise do Serviço Social no Brasil pós-64, $7^{\circ}$ ed., Cortez, São Paulo, 2004.
PONTES, Reinaldo. "Mediação: categoria fundamental para o trabalho do assistente social" In Capacitação em Serviço Social e Política Social, Módulo 4 - Cead/ABEPSS/ CFESS, Brasília, 2000.

Projeto de Estágio Curricular do Curso de Serviço Social - UniFOA, 2003.

VASCONCELOS, Eduardo Mourão \& MORGADO, Rosana. Proposta Conceitual do PAIF: subsídios analíticos e metodológicos na lógica do Sistema Único da Assistência Social - SUAS e do Programa de Atendimento Integral à Família - PAIF/RJ. Governo do Estado do Rio de Janeiro - Secretaria de Estado da Família e da Assistência Social - SEFAS/RJ, 2005.

SERRA, Rose. "O Serviço Social do Rio de Janeiro na crise do Estado brasileiro e em face ao projeto neoliberal" In Crise da Materialidade no Serviço Social, São Paulo: Cortez, 2000.

SPOSATI, Aldaíza. A assistência na trajetória das políticas sociais brasileiras. $6^{\mathrm{a}}$ ed., São Paulo: Cortez, 1995.

Informações bibliográficas:

Conforme a NBR 6023:2002 da Associação Brasileira de Normas Técnicas (ABNT), este texto científico publicado em periódico eletrônico deve ser citado da seguinte forma:

AMORIM, U. A. F.; TAVARES, M. A. S.. Serviço Social: Reflexões sobre as atuais tendências do mercado de trabalho do assistente social a partir de um estudo realizado com os alunos egressos do Curso de Serviço Social - UniFOA. Cadernos UniFOA, Volta Redonda, ano 2, no . 5, dez. 2007. Disponível em: <http://www.unifoa.edu.br/pesquisa/caderno/edicao/05/51.pdf> 